\title{
Forty years of a psychiatric day hospital
}

\author{
Quarenta anos de um hospital de dia de psiquiatria
}

\author{
Rosário Curral, ${ }^{1}$ Rui Lopes,${ }^{2}$ Celeste Silveira, ${ }^{1}$ Andreia Norton, ${ }^{2}$ Isabel Domingues, ${ }^{2}$ Fernando Lopes, ${ }^{3}$ \\ Elisabete Ramos, ${ }^{4}$ António Roma-Torres ${ }^{2}$
}

\begin{abstract}
Introduction: Day hospitals in psychiatry are a major alternative to inpatient care today, acting as key components of community and social psychiatry.

Objective: To study trends in the use of psychiatric day hospitals over the last decades of the 20th century and the first decade of the 21st century, focusing on patient age, sex, and diagnostic group, using data from Centro Hospitalar São João, Porto, Portugal.

Methods: Data corresponding to years 1970 to 2009 were collected from patient files. Patients were classified into seven diagnostic groups considering their primary diagnoses only.

Results: Mean age upon admission rose from $32.7 \pm 12.1$ years in the second half of the 1970 s to $43.5 \pm 12.2$ years in $2005-2009$ ( $p$ for trend $<0.001)$. Most patients were female $(63.2 \%)$, however their proportion decreased from nearly $70 \%$ in the 1970 s to $60 \%$ in the first decade of the 21 st century. In males, until the late 1980s, neurotic disorders (E) were the most common diagnosis, accounting for more than one third of admissions. In the subsequent years, this proportion decreased, and the number of admissions for schizophrenia (C) exceeded $50 \%$ in 20042009. In females, until the late 1980 s, affective disorders (D) and neurotic disorders (E), similarly distributed, accounted for most admissions. From the 1990 s on, the proportion of neurotic disorders (E) substantially decreased, and affective disorders (D) came to represent more than $50 \%$ of all admissions.

Conclusions: Mean age upon admission rose with time, as did the percentage of female admissions, even though the latter tendency weakened in the last 10 years assessed. There was also an increase in the proportion of patients with schizophrenia.
\end{abstract}

Keywords: Day hospital, community psychiatry, mental disorders, mental health.

\begin{abstract}
Resumo
Introdução: Os hospitais de dia em psiquiatria representam atualmente uma das principais alternativas ao internamento, atuando como componentes chave na psiquiatria comunitária e social. Objetivo: Avaliar tendências na utilização de um hospital de dia no período compreendido entre as últimas décadas do século 20 e a primeira década do século 21 , com foco em idade, sexo e grupo diagnóstico, usando dados do Centro Hospitalar São João, Porto, Portugal.
\end{abstract}

Métodos: Dados correspondentes aos anos 1970 a 2009 foram coletados dos prontuários clínicos. Os pacientes foram classificados em sete grupos diagnósticos, tendo em conta o diagnóstico principal.

Resultados: A idade média na admissão aumentou de 32.7 \pm 12.1 anos na segunda metade da década de 1970 para $43.5 \pm 12.2$ anos em 2005-2009 ( $p<0.001$ ). A maioria dos pacientes era do sexo feminino (63.2\%), no entanto sua proporção diminuiu de cerca de $70 \%$ na década de 1970 para $60 \%$ na primeira década do século 21 . Nos homens, até o final dos anos 1980, o grupo das perturbações neuróticas (E) era o diagnóstico mais comum, representando mais de um terço das admissões. Durante os anos seguintes, essa proporção diminuiu, e o número de admissões por esquizofrenia (C) alcançou mais de $50 \%$ no período de 2004-2009. Nas mulheres, até o final dos anos 1980, as perturbações afetivas (D) e as perturbações neuróticas (E), distribuídas similarmente, respondiam pela maioria das admissões. A partir dos anos 1990, a proporção das perturbações neuróticas (E) diminuiu substancialmente, e as perturbações afetivas (D) passaram a corresponder a mais de $50 \%$ do total das admissões. Conclusões: A idade média na admissão aumentou com o tempo, e verificou-se uma maior porcentagem de admissões no sexo feminino, embora esta última tendência tenha sido atenuada nos últimos 10 anos avaliados. Houve também um aumento na proporção de pacientes com esquizofrenia.

Descritores: Hospital de dia, psiquiatria comunitária, transtornos mentais, saúde mental.

\footnotetext{
${ }_{1}$ Psychiatry and Mental Health Clinic, Centro Hospitalar São João, and Department of Clinical Neurosciences and Mental Health, Porto Medical School, Porto, Portugal. ${ }^{2}$ Psychiatry and Mental Health Clinic, Centro Hospitalar São João, Porto, Portugal. ${ }^{3}$ Clinical Coding Service, Centro Hospitalar São João, and Department of Health Information and Decision Sciences (CIDES), Porto Medical School, Porto, Portugal. ${ }^{4}$ Department of Epidemiology, Porto Medical School, Porto, Portugal. The present study was carried out at the Psychiatric Day Hospital of the Psychiatry and Mental Health Clinic at Centro Hospitalar São João, Porto, Portugal. Financial support: none.

Submitted May 01 2013, accepted for publication Dec 02 2013. No conflicts of interest declared concerning the publication of this article.

Suggested citation: Curral R, Lopes R, Silveira C, Norton A, Domingues I, Lopes F, et al. Forty years of a psychiatric day hospital. Trends Psychiatry Psychother. 2014;36(1):52-58. http://dx.doi.org/10.1590/2237-6089-2013-0018
} 


\section{Introduction}

Day hospitals constitute one of the earliest forms of psychiatric community care, and today they are an integral part of social psychiatric policies, especially as a result of the "deinstitutionalization" movement and the consequent disappearance of traditional psychiatric hospitals known as asylums. The concept was created in Russia in the $1930 \mathrm{~s}^{1}$ and spread to America during the 1940 s and $1950 s^{2,3}$ favored by the expansion of "therapeutic community" ideals after the Second World War and by the advent of psych drugs, which allowed better ways of dealing with psychiatric disorders. ${ }^{4}$ They became popular after the setting up of partial hospitalization programs as directed by the Community Mental Health Centers Construction Act in $1963 . .^{5}$ In Europe, they also spread during the 1940 s and 1950 s and reached their peak in the 1970s, when they provided the main alternative to hospital admission. ${ }^{6}$ Notwithstanding, in the 1980 s and 1990s, there was a worldwide decline in the expansion of psychiatric day hospitals, related to evidence of limited cost-effectiveness and to a competition from more radical "non-institutional" alternatives, e.g., assertive community treatment and acute home-based care.7,8 In the last few years, a renewed interest in psychiatric day hospitals has been observed, due to relevant evidence supporting the cost-effectiveness and social advantages of this treatment option. ${ }^{9-14}$

In fact, day hospitals have been as effective as inpatient treatment ${ }^{14-18}$ and have been associated with superior measures of social and functional outcome, as well as prevention and readmission reduction. ${ }^{18-21} \mathrm{~A}$ systematic review found a cost reduction ranging from 20.9 to $36.9 \%$ in relation to inpatient care, associated with greater treatment satisfaction ${ }^{22}$; and a recent update of that study concluded that caring for people in acute day hospitals can achieve substantial reductions in the number of people requiring inpatient care, whilst improving patient outcome. ${ }^{23}$ Similar findings have been found by Kallert et al., who demonstrated a cost reduction of $22 \% .{ }^{14}$ Furthermore, it appears that psychiatric day hospitals are more effective in terms of reducing psychopathology in the short term. ${ }^{3,19}$ Also, there is a reduction of family burden ${ }^{5,24}$ and relapse rates, ${ }^{25}$ and greater subjective quality of life at discharge. A significantly longer admission time, at a mean of 55.7 days compared with 30.5 days in inpatient care, has been documented, and although community-based services tend to be more expensive, higher costs generated better patient outcomes, a more effective reduction of psychopathology, and higher patient satisfaction. ${ }^{19}$

Day hospitals are distinguished from other types of partial hospitalization or day care initiatives such as intensive day treatment programs or long-term support day care centers. ${ }^{26,27}$ In Europe, the majority of psychiatric day hospitals offer social psychiatric-based orientation combined with psychodynamic or behavioral activities, and approximately one third of them are considered as predominantly psychotherapeutic, mainly addressing patients with personality disorders, but also eating, chronic mood, and anxiety disorders. ${ }^{28}$ Treatment programs available depend on treatment ideologies, goals, target populations, and patient diagnosis, illness intensity, and duration. ${ }^{29-33}$

The objective of this study was to describe trends in the use of a psychiatric day hospital, namely Centro Hospitalar São João, Porto, Portugal, and to characterize admissions regarding patient age, sex, and diagnostic group, over 40 years (1970-2009, $n=4,095$ admissions). We also aimed to study the effect of changes over time on the profile of admissions to the psychiatric day hospital assessed.

\section{Description of the current psychiatric day hospital of Centro Hospitalar São João}

\section{General overview}

The day hospital affiliated with the Psychiatry and Mental Health Clinic of Centro Hospitalar São João was opened in 1970, i.e., one of the first created in Portugal. ${ }^{34,35}$ Currently, it provides psychiatric services to a population of about 350,000 individuals from several locations of the city of Porto. It is part of a modern community care system, and operates in coordination with community mental health teams, local agencies, and the local community, and also in close collaboration with family physicians and several public and private institutions.

The partial hospitalization program offered at Centro Hospitalar São João is attended daily by up to 20 patients who spend a substantial part of their day under an active multidisciplinary therapeutic regimen, returning to their homes at the end of the day. As also observed in other parts of Europe, the hospital serves as an alternative to inpatient care in the city of Porto, offering similar treatment, however with an emphasis on social and therapeutic group activities. Moreover, it contributes to the patients' progressive readaptation to life in the community, promoting individual freedom and the preservation of the individuals' identity, and providing a stepping stone to satisfactory domestic and working life. ${ }^{36}$

The hospital also provides intervention in crisis situations, such as grief or unemployment, in which 
Título abreviado: Psychiatric day hospital - Curral et al.

Table 1 - Mean \pm standard deviation of age (years) according to time period and sex

\begin{tabular}{lcccc}
\hline Period of time & Total & Male & Female & p* \\
\hline $1975-1979$ & $32.7 \pm 12.1$ & $32.0 \pm 11.6$ & $33.0 \pm 12.4$ & 0.630 \\
$1980-1984$ & $34.6 \pm 12.3$ & $33.6 \pm 13.3$ & $35.2 \pm 11.7$ & 0.204 \\
$1985-1989$ & $38.0 \pm 14.2$ & $37.1 \pm 14.5$ & $38.6 \pm 14.0$ & 0.248 \\
$1990-1994$ & $39.2 \pm 13.0$ & $36.2 \pm 12.8$ & $41.1 \pm 12.9$ & $<0.001$ \\
$1995-1999$ & $44.0 \pm 13.2$ & $40.5 \pm 12.1$ & $45.6 \pm 13.3$ & $<0.001$ \\
$2000-2004$ & $42.3 \pm 12.3$ & $41.5 \pm 11.3$ & $42.8 \pm 12.9$ & 0.179 \\
$2005-2009$ & $43.5 \pm 12.2$ & $40.5 \pm 11.6$ & $45.7 \pm 12.2$ & $<0.001$ \\
\hline
\end{tabular}

* p-value for the comparison between males and females.

inpatient care is almost inadvisable, and offers an intensive modality of outpatient care for cases in which conventional outpatient care is insufficient. Apart from an organized program of daily treatment and activities for patients, our unit is also actively involved in training young psychiatrists, as well as in teaching undergraduate medical students, occupational therapists, and psychology students.

\section{Facilities}

The psychiatric day hospital has two nursing rooms, several medical offices, a gymnasium, and a room for diverse activities. There is also an area reserved for occupational therapy activities, which includes a kitchen, a snack bar, and several rooms for manual works. Patients have access to an external garden and greenhouse, where several activities take place.

\section{Patient referral, admission, and discharge}

Patients attend the full program 5 days weekly from 9 a.m. to 4 p.m. (working days), with active treatment; the service is closed on weekends. Generally, admission lasts 12 weeks, but some patients require further treatment, coming to the hospital 2-3 days weekly after the initial treatment. Sources of referral include outpatient, inpatient, and consultation-liaison psychiatric departments, and also primary care, other mental health, and third-party providers. Patients are

Table 2 - Distribution (\%) of admissions according to diagnostic group, time period, and sex

\begin{tabular}{|c|c|c|c|c|c|c|c|c|}
\hline \multirow{2}{*}{ Period of time } & \multirow{2}{*}{$\begin{array}{c}\text { Total } \\
\mathbf{n}\end{array}$} & \multicolumn{7}{|c|}{ Diagnostic group } \\
\hline & & $\mathbf{A}$ & B & C & D & $\mathbf{E}$ & $\mathbf{F}$ & $\mathbf{G}$ \\
\hline \multicolumn{9}{|l|}{ Male } \\
\hline $1970-1974$ & 105 & 6.7 & 1.0 & 19.0 & 23.8 & 36.2 & 9.5 & 3.8 \\
\hline $1975-1979$ & 145 & 2.8 & 3.4 & 20.7 & 20.7 & 36.6 & 4.8 & 11.0 \\
\hline $1980-1984$ & 162 & 8.0 & 6.8 & 22.2 & 25.3 & 34.6 & 3.1 & 0 \\
\hline $1985-1989$ & 188 & 5.9 & 5.9 & 22.3 & 23.9 & 35.1 & 6.4 & 0.5 \\
\hline 1990-1994 & 253 & 3.2 & 4.3 & 27.3 & 28.5 & 29.6 & 7.1 & 0 \\
\hline 1995-1999 & 211 & 2.4 & 4.7 & 33.2 & 37.0 & 17.5 & 5.2 & 0 \\
\hline $2000-2004$ & 258 & 3.5 & 19.0 & 32.6 & 26.4 & 10.5 & 6.6 & 1.6 \\
\hline $2005-2009$ & 184 & 4.3 & 7.6 & 53.3 & 20.1 & 7.6 & 7.1 & 0 \\
\hline \multicolumn{9}{|l|}{ Female } \\
\hline $1970-1974$ & 228 & 1.7 & 0.4 & 7.9 & 36.8 & 43.4 & 5.7 & 3.9 \\
\hline $1975-1979$ & 292 & 3.1 & 0.3 & 5.1 & 38.0 & 37.7 & 2.4 & 13.4 \\
\hline $1980-1984$ & 268 & 2.2 & 1.9 & 8.6 & 39.6 & 43.3 & 3.4 & 1.1 \\
\hline $1985-1989$ & 301 & 1.0 & 1.0 & 7.3 & 40.9 & 46.5 & 2.3 & 1.0 \\
\hline $1990-1994$ & 419 & 2.1 & 1.4 & 8.1 & 66.8 & 15.0 & 3.8 & 2.6 \\
\hline 1995-1999 & 463 & 1.5 & 2.6 & 9.9 & 73.9 & 8.0 & 1.7 & 2.4 \\
\hline $2000-2004$ & 366 & 2.5 & 4.6 & 11.2 & 56.0 & 11.5 & 6.0 & 8.2 \\
\hline $2005-2009$ & 252 & 1.6 & 1.2 & 16.7 & 57.9 & 11.9 & 6.0 & 4.8 \\
\hline
\end{tabular}

$\mathrm{A}=$ organic disorders, including symptomatic, mental disorders, and mental retardation; $\mathrm{B}=$ mental and behavioral disorders due to psychoactive substance abuse; $C=$ schizophrenia, schizotypal, and delusional disorders; $D=$ mood (affective) disorders; $E=$ neurotic, stress-related, and somatoform disorders; $F=$ eating disorders and others; $\mathrm{G}=$ adult personality and behavioral disorders. 
Table 3 - Odds ratio ( $95 \%$ confidence interval) of admission for a diagnosis according to time period and sex

\begin{tabular}{|c|c|c|c|c|c|c|c|}
\hline \multirow{2}{*}{$\begin{array}{l}\text { Period of } \\
\text { time }\end{array}$} & \multicolumn{7}{|c|}{ Diagnostic group } \\
\hline & A & B & C & D & E & $\mathbf{F}$ & G \\
\hline \multicolumn{8}{|l|}{ Male } \\
\hline $1970-1974$ & 1 & 1 & 1 & 1 & 1 & 1 & 1 \\
\hline $1975-1979$ & $0.35(0.07-1.35)$ & $3.71(0.59-71.7)$ & $1.11(0.59-2.11)$ & $0.83(0.46-1.53)$ & $1.02(0.60-1.72)$ & $0.48(0.17-1.30)$ & $3.13(1.11-11.2)$ \\
\hline $1980-1984$ & $1.09(0.39-3.28)$ & $7.58(1.44-139)$ & $1.21(0.66-2.27)$ & $1.08(0.61-1.94)$ & $0.93(0.56-1.56)$ & $0.30(0.09-0.88)$ & * \\
\hline 1985-1989 & $0.73(0.25-2.28)$ & $6.46(1.23-119)$ & $1.22(0.68-2.25)$ & $1.00(0.58-1.78)$ & $0.95(0.58-1.58)$ & $0.65(0.27-1.59)$ & $0.14(0.01-0.9))$ \\
\hline 1990-1994 & $0.20(0.04-0.76)$ & $4.73(0.90-87.0)$ & $1.59(0.92-2.85)$ & $1.27(0.76-2.18)$ & $0.74(0.46-1.21)$ & $0.73(0.33-1.69)$ & $*$ \\
\hline 1995-1999 & $0.24(0.05-0.92)$ & $5.17(0.97-95.7)$ & $2.11(1.22-3.79)$ & $1.88(1.12-3.23)$ & $0.37(0.22-0.64)$ & $0.52(0.21-1.29)$ & * \\
\hline $2000-2004$ & $0.38(0.12-1.27)$ & $24.2(5.18-430)$ & $2.02(1.19-3.60)$ & $1.13(0.67-1.94)$ & $0.20(0.12-.036)$ & $0.66(0.30-1.55)$ & $3.94(0.09-1.70)$ \\
\hline 2005-2009 & $0.74(0.25-2.32)$ & $8.5(1.67-155)$ & $4.79(2.76-8.61)$ & $0.80(0.45-1.43)$ & $0.14(0.07-0.28)$ & $0.72(0.30-1.74)$ & * \\
\hline \multicolumn{8}{|l|}{ Female } \\
\hline $1970-1974$ & 1 & 1 & 1 & 1 & 1 & 1 & 1 \\
\hline $1975-1979$ & $2.11(0.60-9.72)$ & $0.78(0.03-19.8)$ & $0.63(0.31-1.28)$ & $1.05(0.74-1.51)$ & $0.79(0.55-1.12)$ & $0.41(0.15-1.01)$ & $4.16(1.92-10.4)$ \\
\hline 1980-1984 & $1.14(0.25-5.82)$ & $4.32(0.69-83.0)$ & $1.10(0.58-2.11)$ & $1.12(0.78-1.62)$ & $0.99(0.70-1.42)$ & $0.58(0.23-1.36)$ & $0.24(0.04-0.99)$ \\
\hline $1985-1989$ & $*$ & $2.28(0.29-46.2)$ & $0.92(0.48-1.77)$ & $1.18(0.83-1.68)$ & $1.13(0.80-1.59)$ & $0.39(0.14-0.97)$ & $0.21(0.03-0.88)$ \\
\hline 1990-1994 & $1.46(0.42-6.70)$ & $3.29(0.56-62.3)$ & $1.03(0.57-1.90)$ & $3.43(2.45-4.82)$ & $0.22(0.16-0.33)$ & $0.65(0.31-1.41)$ & $0.46(0.14-1.39)$ \\
\hline 1995-1999 & $0.98(0.40-6.84)$ & $6.03(1.18-110)$ & $1.28(0.74-2.32)$ & $4.80(3.43-6.77)$ & $0.11(0.07-0.17)$ & $0.29(0.11-0.70)$ & $0.34(0.10-1.09)$ \\
\hline $2000-2004$ & $1.46(.040-6.84)$ & $11.1(2.25-200)$ & $1.47(0.84-2.69)$ & $2.18(1.56-3.07)$ & $0.17(0.11-0.25)$ & $1.06(0.53-2.20)$ & $1.07(0.42-2.91)$ \\
\hline 2005-2009 & $0.60(0.08-3.62)$ & $2.71(0.34-55.1)$ & $2.31(1.31-4.24)$ & $2.32(1.61-3.35)$ & $0.17(0.11-0.27)$ & $1.04(0.48-2.26)$ & $0.12(0.01-0.71)$ \\
\hline
\end{tabular}

$\mathrm{A}=$ organic disorders, including symptomatic, mental disorders, and mental retardation; $\mathrm{B}=$ mental and behavioral disorders due to psychoactive substance abuse; $C=$ schizophrenia, schizotypal, and delusional disorders; $D=$ mood (affective) disorders; $E=$ neurotic, stress-related, and somatoform disorders; $F=$ eating disorders and others; $\mathrm{G}=$ adult personality and behavioral disorders.

Results in bold indicate statistically significant differences.

* The small number of patients did not allow to quantify the odds ratio.

always selected and screened for suitability to admission in a programmed schedule; emergency admissions are not allowed. At the time of discharge, the functional status of patients is expected to be improved to the point of readiness for their life in the community, and they usually continue treatment through outpatient or support care (e.g., group therapy).

\section{Treatment setting}

The psychiatric day hospital of Centro Hospitalar São João can provide diagnostic and treatment services for acutely ill patients or those experiencing some degree of remission from acute illness. Moreover, it can provide maintenance and rehabilitation treatment for patients with chronic psychiatric illnesses, as described elsewhere. ${ }^{33}$ The population served by the hospital is racially, ethnically, and financially diverse, covering all age groups. Exclusion criteria include homelessness, primary diagnosis of an addictive disorder, suicide risk and life-threatening behaviors, symptom severity requiring inpatient treatment, and auto- or heteroaggressive behaviors. Upon admission, the participants' personal goals and expectations are discussed, and the patterns of communication with family members are established.
The daily intervention follows a structured, intensive group-based program, including a range of verbal, non-verbal, creative, and occupational therapy interventions. It includes physical treatment (medication), hospital services (psychiatric, physical, and neurological examinations), auxiliary diagnostic tools (electroencephalogram, axial tomography, magnetic resonance, and others), day services, community mental health professionals/interventions (psychiatrist, psychologist, community psychiatric nurse, individual or group counseling, behavioral therapy, social therapy, family therapy), community health professionals/interventions (occupational therapist, art therapist), support services (social worker, home care worker, and family support), and legal services (forensic assessment). Liaison meetings are regularly held, with continuous assessment and feedback, to ensure that health professionals are properly supervised.

Family members also receive psychological support during the patient's acute day hospitalization. Treatment can be extended to support groups for families and patients, preventing caregiver burnout and making all family members fully involved. Weekly, the team meets to discuss each patient's individual therapeutic plan and to regulate the staff's group dynamics. 
Table 4 - Median admission time in days (25th and 75th percentile) over time according to diagnostic group $(p<0.001$ for $C, D$, and E only)

\begin{tabular}{llll}
\hline Period of time & C & D & E \\
\hline $1970-1974$ & $36(25.5 ; 47.25)$ & $37(23 ; 65.5)$ & $39(24 ; 79)$ \\
$1975-1979$ & $58(37 ; 81)$ & $46(26.5 ; 72)$ & $49(25 ; 71)$ \\
$1980-1984$ & $48(27 ; 71)$ & $39(22 ; 64)$ & $37(22 ; 61.5)$ \\
$1985-1989$ & $31(21 ; 46)$ & $39(22 ; 49)$ & $35.5(24 ; 46)$ \\
$1990-1994$ & $36(16 ; 46)$ & $37(24 ; 46)$ & $31.5(19 ; 44.25)$ \\
$1995-1999$ & $41.5(24.25 ; 50)$ & $38(24 ; 48)$ & $41(24.5 ; 53)$ \\
$2000-2004$ & $35(18 ; 52)$ & $36(22 ; 50)$ & $37(18.5 ; 54.5)$ \\
$2005-2009$ & $58(29.25 ; 109.25)$ & $48(25 ; 77)$ & $64(29 ; 90.25)$ \\
\hline
\end{tabular}

$\mathrm{C}=$ schizophrenia, schizotypal, and delusional disorders; $\mathrm{D}=$ mood (affective) disorders; $\mathrm{E}=$ neurotic, stress-related, and somatoform disorders.

\section{Data collection and statistical analysis}

Data on age, sex, diagnosis, and admission time in days were collected from the patients' files after discharge. The study was approved by the local ethics committee.

Diagnoses were coded according to the International Classification of Diseases, 10th edition (ICD-10). ${ }^{37}$ For this analysis, only primary diagnoses were considered, and classified into the follow categories: A) organic disorders, including symptomatic, mental disorders, and mental retardation; B) mental and behavioral disorders due to psychoactive substance abuse; C) schizophrenia, schizotypal, and delusional disorders; D) mood (affective) disorders; E) neurotic, stress-related, and somatoform disorders; F) eating disorders and others; and G) adult personality and behavioral disorders.

Because of the way how clinical processes were organized until 1989, it was not possible to reliably identify each patient until that year. Therefore, for the period between 1970 and 1989, each event was considered to correspond to one admission; from 1990 to 2009, in turn, data on both admissions and patients were available. The total number of admissions was 4,097, but eight records were excluded due to missing information on diagnosis (three from 1970-1989 and five from 1990-2009). For the analyses, a total of 4,089 admissions were considered, 1,521 from 1970-1989 and 2,568 from 1990-2009. The 2,568 admissions from 1990-2009 corresponded to 2,373 patients; only the first admission was considered in the analysis by patient.

The chi-square test was used to assess differences over time. The effect of time was quantified using logistic regression, with odds ratio (OR) and respective $95 \%$ confidence intervals $(95 \% \mathrm{CI})$. In the first model, in order to quantify the effect of time by decade, time was considered a categorical variable (the first decade was used as reference); a second model was used, considering time as a continuous variable, to estimate the linear trend of the difference ( $p$-value for trend).

Data analyses were performed using the Statistical Package for the Social Sciences (SPSS) version 18 and $\mathrm{R}^{\circledR}$ statistical software. Significance was set at 5\% $(p<0.05)$.

\section{Results}

From 1970 to 2009, of the total of 4,095 admissions, $2,589(63.2 \%)$ corresponded to females. The proportion of females was higher throughout the study period, but decreased from nearly $70 \%$ in the 1970 s to $60 \%$ in the first decade of the 21st century. Mean age \pm standard deviation rose from $32.7 \pm 12.1$ years in the second half of the 1970 s to $43.5 \pm 12.2$ years in $2005-2009$ ( $p$ for trend $<0.001$ ). In all periods, females showed a higher mean age, but the difference reached statistical significance in the 1990 s only (Table 1 ). Mean occupancy rates have risen from $37 \%$ in the first period to $75 \%$ at the final year range analyzed.

Table 2 shows the distribution of admissions according to diagnostic category, time period, and sex. In males, until the late 1980s, neurotic disorders (E) were the most common diagnosis, accounting for more than one third of admissions. In the subsequent years, this proportion decreased, and the proportion of admissions for schizophrenia (C) increased, reaching more than $50 \%$ in 2004-2009. In females, until the late 1980s, affective disorders (D) and neurotic disorders (E), similarly divided, accounted for most of the total admissions. As of the 1990s, the proportion of neurotic disorders (E) substantially decreased, and affective disorders (D) came to represent more than $50 \%$ of the total admissions.

Table 3 shows increases and decreases in the odds of having a diagnosis over time, considering the first period as reference. Results for the less prevalent diagnoses should be read with caution, due to the possibility of inaccurate estimates, as suggested by the wide $95 \%$ CI ranges. 
Finally, the evolution of length of hospital stay was analyzed considering the three diagnostic groups with the largest number of patients (schizophrenia [C], affective [D] and neurotic disorders [E]) (Table 4). Even though there were variations over time, the changes did not show a clear trend. Median admission time rose in the three categories in the last period assessed (from 35,36 , and 37 in 2000-2004 to 58, 48, and 64 in 20052009 for C, D, and E, respectively).

\section{Discussion}

Globally, it is evident that, over the period studied, there was a higher percentage of female patients admitted compared to males (63.2 vs. $36.8 \%$ ), even though this difference weakened in the last 10 years assessed and was not verified for all diagnostic groups. This trend towards female predominance has also been observed in other studies, e.g., in a 2001 Portuguese psychiatric census focusing on outpatients ( 58.5 vs. $41.5 \%){ }^{38}$

The higher prevalence of schizophrenia (C) in the male sex is in accordance with evidence found in recent literature. ${ }^{39,40}$ Relative to the distribution of diagnostic groups, our results are, once again, comparable to the results of the 2001 Portuguese psychiatric census: in our study, over 40 years, the group of affective disorders (D) accounted for a higher percentage of admissions $(43.8 \%)$, followed by neurotic disorders (E) $(24.5 \%)$ and schizophrenia (C) (16.8\%) - figures that are similar to the results mentioned for the Portuguese outpatients $\left(30.8,22.8\right.$, and $12.4 \%$, respectively). ${ }^{38}$

The increase in median admission time in schizophrenia (C) (from 35 days in 2000-2004 to 58 in 2005-2009) is probably related to a stronger emphasis, in the last years assessed, on psychosocial rehabilitation programs (Table 4). Over time, average occupancy rates raised from 37 to $75 \%$. Despite a decrease in the number of admissions in the last period, the overall increase was probably due to longer admission times in that period. In the period of 2000-2004, the increased number of admissions in the group of mental and behavioral disorders due to psychoactive substance abuse (B) (more pronounced in men, with $19 \%$ of admissions) was probably due to the restructuring of the substance abuse outpatient services.

Comorbidity and dual diagnoses were not considered in data collection; rather, only primary diagnoses were collected from patients' records. This may be seen as a possible limitation of the study, as dual diagnoses may be involved or have a direct influence on readmission rates.

The history of the psychiatric day hospital at Centro Hospitalar São João can be analyzed considering four great periods: a) 1970-1979, structuring - in this period, only psychiatric treatment was available; b) 1980-1989, differentiation - in 1979, the inpatient unit opened, resulting in the need to distinguish between operating criteria for full vs. partial hospitalization; c) 1990-2004, consolidation - in this period, the use of selective serotonin reuptake inhibitors (SSRIs), antidepressants (fluoxetine in 1990), and second-generation antipsychotics (clozapine in 1989 and risperidone in 1994) was introduced, enabling a more effective treatment of affective disorders in the outpatient setting and increasing the availability of social therapy and psychosocial rehabilitation in schizophrenic disorders (furthermore, the population referral area was expanded by the Portuguese Mental Health Act of 1998, determining expansion of the area of the municipality of Maia to include the Águas Santas village, Porto Oriental areas [Bonfim and Campanhã villages], each one comprising about 100,000 inhabitants; and closure of the local large psychiatric hospital in 2003 [Hospital Conde Ferreira ${ }^{38}$ ]); and d) 2005-2009, specialization - rehabilitation of chronic mental patients, new board taking over the day hospital in 2006, and new board taking over the Psychiatry and Mental Health Clinic in 2007.

In the last years assessed, the main objective of the unit was the care of schizophrenic patients. Therefore, the increased prevalence of patients with schizophrenia in the hospital is due to the new paradigm of the unit, with a stronger emphasis on intensive treatment via rehabilitation programs. In fact, due to the chronic course of schizophrenia, these patients are major consumers of day care services and draw great benefits from a day hospital with rehabilitation goals and active and practical therapies, in addition to occupational therapy.

Over its history, the psychiatric day hospital never stopped being an alternative to inpatient care. Despite changes observed in the availability of therapeutic resources, legislation, national and regional health administration options, and those related to leadership responsibilities, it is worth pointing out that there has been a remarkable continuity in its services.

In sum, the psychiatric day hospital at Centro Hospitalar São João can offer day treatment programs for those with acute and severe psychiatric problems, integrated in a modern community mental healthcare system with community-directed services. Its privileged type of service, situated between local community and inpatient care, allows patients to keep in contact with the real world, and can also provide useful follow-up services for those recently discharged but still in need of intensive support.

\section{Conclusions}

Over 40 years of functioning, median age upon admission statistically rose, and even though the 
proportion of women has always been higher than men, this difference weakened in the last 10 years assessed. The distribution of diagnostic groups showed a rise, in the last years assessed, of patients with a diagnosis of schizophrenia, and a fall of patients with neurotic disorders, more pronounced in the male sex.

By describing the characteristics of the admissions in this specific unit, this study opens the door for future research in different directions. Despite the recent emergence of alternative options such as acute homebased care provided by a specialized crisis team, day hospitals still seem to be cheaper and perform better in providing psychiatric care. Further studies are needed to better assess its advantages and to identify the patients who can benefit most from it.

\section{References}

1. Cameron DE. The day hospital; an experimental form of hospitalization for psychiatric patients. Mod Hosp. 1947;69:60-2.

2. Volovik VM, Zachepitskii RA. Treatment, care, and rehabilitation of the chronic mentally ill in the U.S.S.R. Hosp Community Psychiatry. 1986;37:280-2.

3. Sadock BJ, Sadock VA, Ruiz P, Kaplan HI. Kaplan \& Sadock's comprehensive textbook of psychiatry. 9th ed. Philadelphia: Lippincott Williams \& Wilkins; 2009.

4. Shorter E. A historical dictionary of psychiatry. New York: Oxford University Press; 2005.

5. Pang J Jr. Partial hospitalization. An alternative to inpatient care. Psychiatr Clin North Am. 1985;8:587-95.

6. Creed F, Black D, Anthony P. Day-hospital and community treatment for acute psychiatric illness. A critical appraisal. $\mathrm{Br}$ J Psychiatry. 1989;154:300-10

7. Krizay J. Partial Hospitalization: facilities, cost and utilization. Washington, DC: American Psychiatric Association, Office of Economic Affairs; 1989.

8. Vaughan PJ. The disordered development of day care in psychiatry. Health Trends. 1983;15:91-4

9. Provost $D$, Bauer $A$. Trends and developments in public psychiatry in France since 1975. Acta Psychiatr Scand Suppl. 2001;(410):63-8.

10. Puzynski S, Moskalewicz J. Evolution of the mental health care system in Poland. Acta Psychiatr Scand Suppl. 2001;(410):69-73.

11. Schene AH, Faber AM. Mental health care reform in The Netherlands. Acta Psychiatr Scand Suppl. 2001;(410):74-81.

12. Vázquez-Barquero JL, García J, Torres-González F. Spanish psychiatric reform: what can be learned from two decades of experience? Acta Psychiatr Scand Suppl. 2001;(410):89-95.

13. Briscoe J, McCabe R, Priebe S, Kallert S. A national survey of psychiatric day hospitals. Psychiatr Bull. 2004;28:160-3.

14. Kallert TW, Schönherr R, Schnippa S, Matthes C, Glöckner M, Schützwohl M. [Direct costs of acute day hospital care: results from a randomized controlled trial]. Psychiatr Prax. 2005;32:132-41.

15. Schene AH, Gersons BP. Effectiveness and application of partial hospitalization. Acta Psychiatr Scand. 1986;74:335-40.

16. Sledge WH, Tebes J, Rakfeldt J, Davidson L, Lyons L, Druss B. Day hospital/crisis respite care versus inpatient care, Part I: Clinical outcomes. Am J Psychiatry. 1996;153:1065-73.

17. Dick $P$, Cameron L, Cohen D, Barlow M, Ince A. Day and full time psychiatric treatment: a controlled comparison. $\mathrm{Br}$ J Psychiatry. 1985:147:246-9.

18. Creed F, Black D, Anthony P, Osborn M, Thomas P, Tomenson B. Randomised controlled trial of day patient versus inpatient psychiatric treatment. BMJ. 1990;300:1033-7.

19. Priebe S, Jones G, McCabe R, Briscoe J, Wright D, Sleed M, et al. Effectiveness and costs of acute day hospital treatment compared with conventional in-patient care: randomised controlled trial. $\mathrm{Br}$ J Psychiatry. 2006;188:243-9.

20. Kallert TW, Priebe S, McCabe R, Kiejna A, Rymaszewska J, Nawka $P$, et al. Are day hospitals effective for acutely ill psychiatric patients? A European multicenter randomized controlled trial. J Clin Psychiatry. 2007;68:278-87.
21. Priebe S, McCabe R, Schützwohl M, Kiejna A, Nawka P, Raboch J, et al. Patient characteristics predicting better treatment outcomes in day hospitals compared with inpatient wards. Psychiatr Serv. 2011;62:278-84.

22. Marshall M, Crowther R, Almaraz-Serrano A, Creed F, Sledge W, Kluiter $\mathrm{H}$, et al. Systematic reviews of the effectiveness of day care for people with severe mental disorders: (1) acute day hospital versus admission; (2) vocational rehabilitation; (3) day hospital versus outpatient care. Health Technol Assess. 2001;5:1-75.

23. Marshall M, Crowther R, Sledge WH, Rathbone J, Soares-Weiser K. Day hospital versus admission for acute psychiatric disorders. Cochrane Database Syst Rev. 2011:CD004026.

24. Parker S, Knoll JL, 3rd. Partial hospitalization: an update. Am J Psychiatry. 1990;147:156-60.

25. Moscowitz IS. The effectiveness of day hospital treatment: a review. J Community Psychol. 1980;8:155-64.

26. Rosie JS. Partial hospitalization: a review of recent literature. Hosp Community Psychiatry. 1987;38:1291-9.

27. Hoge MA, Davidson L, Hill WL, Turner VE, Ameli R. The promise of partial hospitalization: a reassessment. Hosp Community Psychiatry. 1992;43:345-54.

28. Karterud S, Wilberg T. From general day hospital treatment to specialized treatment programmes. Int Rev Psychiatry. 2007;19:39-49.

29. Kallert TW, Glöckner M, Priebe S, Briscoe J, Rymaszewska J, Adamowski $\mathrm{T}$, et al. A comparison of psychiatric day hospitals in five European countries: implications of their diversity for day hospital research. Soc Psychiatry Psychiatr Epidemiol. 2004;39:777-88.

30. Schene AH. Partial hospitalization. In: Thornicroft E, Szmukler G, eds. Textbook of community psychiatry. Oxford: Oxford University Press; 2001:283-93.

31. Schene AH, van Lieshout PA, Mastboom JC. Different types of partial hospitalization programs: results of a nationwide survey in The Netherlands. Acta Psychiatr Scand. 1988;78:515-22.

32. Mbaya $P$, Creed $F$, Tomenson B. The different uses of day hospitals. Acta Psychiatr Scand. 1998;98:283-7.

33. Rosie JS, Azim HF, Piper WE, Joyce AS. Effective psychiatric day treatment: historical lessons. Psychiatr Serv. 1995;46:1019-26.

34. Fernandes da Fonseca A, Rente $F$, Roma-Torres A, Geada JD, Barbedo de Oliveira A, Miranda L, Saraiva A. Serviço de Psiquiatria do Hospital São João - A Unidade do Hospital de Dia. Boletim do Departamento de Saúde Mental da Faculdade de Medicina do Porto. 1980(II. a Série, Outubro-Dezembro).

35. Barreto J. Reorganização: linhas pragmáticas. Porto: Hospital São João; 2005.

36. Gelder MG, Andreasen NC, Lopez-Ibor J], Geddes JR. New Oxford textbook of psychiatry. 2nd ed. Oxford: Oxford University Press; 2009.

37. The ICD-10 Classification of Mental and Behavioural Disorders: clinical descriptions and diagnostic guidelines. World Health Organization; 1992.

38. Heitor MJ, Barreto A, Brito I, Cepeda T, Correia H. Rede de referenciação de psiquiatria e saúde mental. Lisboa: Direcção Geral de Sáude; 2004. http://www.dgs.pt/upload/membro.id/ ficheiros/i007439.pdf

39. McGrath J, Saha S, Welham J, El Saadi O, MacCauley C, Chant D. A systematic review of the incidence of schizophrenia: the distribution of rates and the influence of sex, urbanicity, migrant status and methodology. BMC Med. 2004;2:13.

40. Aleman A, Kahn RS, Selten JP. Sex differences in the risk of schizophrenia: evidence from meta-analysis. Arch Gen Psychiatry. 2003;60:565-71.

\section{Correspondence:}

Rui Lopes

Clinic of Psychiatry and Mental Health

Centro Hospitalar São João

Alameda Professor Hernâni Monteiro, 4200/319

Porto, Portugal

Tel./Fax: +351225512100 / +351225512334

Email: rui.lopess@gmail.com 